\title{
CLINICAL AND RADIOLOGICAL CORRELATION OF PULMONARY MANIFESTATIONS IN PATIENTS WITH ANKYLOSING SPONDYLITIS
}

Julia Cristina Souza Alves (Universidade Federal do Amazonas, Manaus, AM, Brasil), Isabelle Louise Cruz Lopo Figueiredo (Universidade Federal do Amazonas, Manaus, AM, Brasil), Raissa Pires Medeiros (Universidade Federal do Amazonas, Manaus, AM, Brasil), Matheus Diniz Araújo Teixeira (Universidade Federal do Amazonas, Manaus, AM, Brasil), Maykom Lira Barbosa (Universidade Federal do Amazonas, Manaus, AM, Brasil), Gabriel Pacífico Seabra Nunes (Universidade Nilton Lins, Manaus, AM, Brasil), Mario Sergio Monteiro Fonseca (Universidade Federal do Amazonas, Manaus, AM, Brasil), Felipe Augusto Silva Gama (CEMED Imagem, Manaus, AM, Brasil), Sandra Lucia Euzébio Ribeiro (Universidade Federal do Amazonas, Manaus, AM, Brasil)

\section{BACKGROUND}

The incidence of pulmonary manifestations in the Ankylosing Spondylitis (AS), according to the literature, can reach up to $30 \%$. The pulmonary involvement in AS may occur in several clinical forms, as for the interstitial involvement of the lung, it is possible to emphasize Apical Pulmonary Fibrosis, which is usually installed at least 15 years after the onset of articular manifestations. The use of diagnostic imaging methods are extremely widespread these days, with emphasis being given to Chest Radiography and Computed Tomography, the latter being highly sensitive.

\section{MATERIALS AND METHODS}

The study is a cross-sectional, prospective, descriptive and uncontrolled study, with follow-up of diagnosed cases of AS in 2018 and early 2019. All 29 subjects involved in the research had their epidemiological data (age, gender and disease time) and clinical (lung complaints, personal and family history of lung disease) evaluated through a form applied at the time of the ambulatory consultation. The subjects involved in the study were submitted to Radiography and Thoracic Computed Tomography.

\section{RESULTS}

We studied 29 patients, with a mean age of 44.4 years, predominantly male (75.9\%). The disease duration presented a mean of 14.8 years, the predominant form of disease being axial (51.75\%). Smoking was present in $13.8 \%$ of the patients, while ex-smoking was described in $24.1 \%$ of the cases. Only 13 (44.8\%) patients reported respiratory complaints, the most frequently reported symptom being cough (20.7\%), followed by dyspnoea (13.8\%) and chest pain (13.8\%). Most patients did not report previous history or current respiratory system related comorbidities. We observed radiographic changes in only 2 (6.9\%) patients, with the presence of nodule and pulmonary infiltrate. Of the alterations found in HRCT, $48.3 \%$ were abnormal, including opacity, apical fibrosis and pulmonary nodule.

\section{CONCLUSION}

This study showed that there was no correlation between disease time and pulmonary impairment, since the average in years of disease is lower than the literature reports. It is known that the pulmonary manifestations in AS are commonly asymptomatic, such affirmation can be confirmed by the high numbers of asymptomatic patients, associated with a high frequency of tomography alterations. In addition, it was noticed that the tomography has a greater sensitivity in the identification of parenchyma lesions than the chest X-ray. Therefore, the rheumatologist must be aware of the pulmonary involvement in these patients with AS. 